\title{
Compensatory responses induced by oxidative stress in Alzheimer disease
}

\author{
PAULA I. MOREIRA ${ }^{1,2}$, XIONGWEI ZHU ${ }^{1}$, QUAN LIU ${ }^{1}$, KAZUHIRO HONDA $^{1}$, \\ SANDRA L. SIEDLAK ${ }^{1}$, PEGGY L. HARRIS ${ }^{1}$, MARK A. SMITH ${ }^{1}$ and GEORGE PERRY ${ }^{1}$
}

${ }^{1}$ Institute of Pathology, Case Western Reserve University, 2085 Adelbert Road, Cleveland, OH 44106 USA;
${ }^{2}$ Center for Neuroscience and Cell Biology of Coimbra, University of Coimbra, 3004-517 Coimbra, Portugal

\begin{abstract}
Oxidative stress occurs early in the progression of Alzheimer disease, significantly before the development of the pathologic hallmarks, neurofibrillary tangles and senile plaques. In the first stage of development of the disease, amyloid- $\beta$ deposition and hyperphosphorylated tau function as compensatory responses and downstream adaptations to ensure that neuronal cells do not succumb to oxidative damage. These findings suggest that Alzheimer disease is associated with a novel balance in oxidant homeostasis.
\end{abstract}

Key terms: Alzheimer disease, antioxidant therapy, mitochondria, oxidative stress, redox metals

\section{INTRODUCTION}

Alzheimer disease (AD) is a common and complex neurodegenerative disorder that affects approximately 15 million people worldwide (Mayeux and Sano, 1999). Aging is the major risk factor for this disease that coexists with other causes of cognitive decline, particularly vascular dementia. The neuropathological hallmarks of AD are synapse abnormalities, intracellular neurofibrillary tangles (NFT) containing mainly polymerized and hyperphosphorylated tau protein, and the accumulation of extracellular amyloid plaques containing mainly amyloid- $\beta(\mathrm{A} \beta)$. $\mathrm{AD}$ is devastating, and despite great strides in recent years, its causes and mechanisms are still puzzling. There is accumulating evidence, however, that oxidative stress plays an important role in the disease pathophysiology. While intracellular oxidative balance is tightly regulated, the activation of multiple signaling pathways and the upregulation of compensatory mechanisms therefore would be expected to occur in neurons from AD patients.
Oxidative stress is a prominent event in the development of Alzheimer disease

Historically, efforts to understand oxidative status have focused on the concept of oxidative stress, i.e., the breaching of oxidant defenses with consequent cellular detrimental effects. According to this definition, the detection of damage resulting from reactive oxygen or nitrogen species indicates the existence of oxidative stress. However, this definition fails to consider the ability of living systems to dynamically regulate their defense mechanisms in response to oxidative stress. Therefore, increases in oxidative damage do not indicate that the cell is succumbing to oxidative stress given that the cell may have increased its defenses sufficiently to compensate for the increased flux of reactive species responsible for the damage. This concept is outlined critically by evidence suggesting that cells failing to compensate for oxidative imbalance enter into apoptosis, which in turn leads to death within hours. It thus follows that cells can only experience oxidative stress for short periods of time 
before rapidly dying (Perry et al., 1998a; Perry et al., 1998b). In chronic degenerative disorders, such as AD, the cells experiencing increased oxidative damage must develop compensatory responses aimed to avoid or, at least, reduce cellular damage or death.

It has been shown that increased oxidative damage is a prominent and early feature of vulnerable neurons in AD (Smith et al., 1997a; Smith et al., 1997b). Over the past decade, oxidative stress-related modifications of macromolecules have been described in association with the susceptible neurons of AD. Such modifications include advanced glycation end products (Smith et al., 1994), nitration (Smith et al., 1997b), lipid peroxidation adduction products (Montine et al., 1996; Sayre et al., 1997), carbonylmodified neurofilament protein and free carbonyls, as well as glycation and glycoxidation products (Castellani et al., 2001; Smith et al., 1994; Smith et al., 1995). Levels of these markers are initially elevated following some unknown triggering neuronal event, but these levels soon decrease as the disease progresses to advanced AD (Perry et al., 2002). Together, these findings suggest that increased oxidative damage is not the terminal sequelae of the disease but instead plays an initial role. They also suggest that damage does not mark further destruction by reactive species and is instead marked by a broad array of increased cellular defenses (Perry et al., 2002). It can be argued that in AD these defenses are responsible for the reduction of damage if we view $A D$ in isolation. When seen in the context of other conditions where reactive oxygen and nitrogen species are involved and damage is either limited or absent, the oxidative damage noted in $\mathrm{AD}$ may be better thought of as homeostatic, i.e., oxidative damage could initiate signal transduction pathways that manipulate cellular responses to stress, which are characterized by increased levels of reactive oxygen and nitrogen species (Perry et al., 2002).

\section{Mitochondria is one major source of oxidative stress}

Extensive evidence indicates that cerebral metabolism is reduced in AD (Kalaria et al.,
1988), placing mitochondria as a key player in this scenario (Hirai et al., 2001). Mitochondria are essential organelles for neuronal function because the limited glycolytic capacity of these cells makes them highly dependent on aerobic oxidative phosphorylation for their energetic needs. However, oxidative phosphorylation is a major source of endogenous, toxic-free radicals, including hydrogen peroxide $\left(\mathrm{H}_{2} \mathrm{O}_{2}\right)$, hydroxyl $(\bullet \mathrm{OH})$ and superoxide $\left(\mathrm{O}_{2}^{-\bullet}\right)$ that are products of normal cellular respiration (Wallace, 1999). Reactive species generated by mitochondria have several cellular targets including mitochondrial components themselves (lipids, proteins, and DNA). The lack of histones in mitochondrial DNA (mtDNA) and diminished capacity for DNA repair render mitochondria an easy target for oxidative stress events. By releasing high levels of $\mathrm{H}_{2} \mathrm{O}_{2}$, dysfunctional mitochondria promote the interaction between redox metals and oxidative response elements (Zhu et al., 2004). The role of mitochondria in AD were studied in our laboratory using in situ hybridization to mitochondrial DNA, immunocytochemistry of cytochrome oxidase, and morphometry of electron micrographs of biopsy specimens to characterize the mitochondrial abnormalities in AD (Hirai et al., 2001; Castellani et al., 2002). We found that the neurons showing increased oxidative damage in AD also possess a striking and significant increase in mtDNA and cytochrome oxidase. Surprisingly, much of the mtDNA and cytochrome oxidase is found in the neuronal cytoplasm, and in the case of mtDNA, the vacuoles associated with lipofuscin, whereas morphometric analysis showed that mitochondria are significantly reduced in AD. We also observed an overall reduction in microtubules in $\mathrm{AD}$ compared to controls (Cash et al., 2003). Altogether, these data indicate that the abnormal mitochondrial turnover, as indicated by increased perikaryal mtDNA and mitochondrial protein accumulation in the face of reduced numbers of mitochondria, could be due to a defective microtubule metabolism resulting in deficient mitochondrial transport in the axon. This may, in turn, set up a pathological cascade of events in the perikaryal mitochondria. 
Accumulating evidence indicate that heme oxygenase-1 (HO-1) is induced in AD brains (Premkumar et al., 1995; Takeda et al., 2004). HO-1 catalyzes the conversion of heme to biliverdin and iron. Biliverdin, in turn, is reduced to bilirubin, an antioxidant. Since HO-1 is induced in proportion to the level of heme (Keyse and Tyrrell, 1989), the induction of $\mathrm{HO}-1$ suggests that there may be abnormal turnover of heme in AD. This idea is consistent with the mitochondrial abnormalities associated with $\mathrm{AD}$ since it is well known that many heme-containing enzymes are found in mitochondria. As previously discussed, our ultrastructural studies centered on mitochondria suggest a high rate of mitochondrial turnover and redox activity in the residual body of lipofuscin (Hirai et al., 2001), with lysosomes the probable sources of heme. In turn, the increase in heme induces synthesis of more HO-1, suggesting that mitochondrial turnover promotes oxidative stress via increases of redox-active iron (Honda et al., 2004).

Furthermore, we observed that oxidized nucleic acids are commonly observed in the cytoplasm of the neurons that are particularly vulnerable to degeneration in sporadic AD (Nunomura et al., 1999b; Nunomura et al., 2001) and familial AD (Nunomura et al., 2004), which suggest a link between oxidative stress and not only age-associated degenerative diseases but also neurodegeneration linked to genetic factors. $8 \mathrm{OHG}$, a marker of nucleic acids oxidation, is likely to form at the site of $\bullet \mathrm{OH}$ production, a process dependent on redox-active, metalcatalyzed reduction of $\mathrm{H}_{2} \mathrm{O}_{2}$, together with cellular reductants such as ascorbate or $\mathrm{O}_{2}^{-}$. Interestingly, the levels of $8 \mathrm{OHG}$ are inversely related to the extent of $A \beta$ deposits (Nunomura et al., 1999b), suggesting a complex interplay between $\mathrm{A} \beta$ and redox metal activity that may be critical to metal dynamics within the neuronal cytoplasm. A possible key element linking these dynamics is mitochondria within neuronal cells.

\section{Oxidative Stress Induces Cellular Compensatory Responses}

Oxidative modification and response are controlled events that play critical homeostatic roles as a reaction to oxidative stress or even more fundamental abnormalities. This view is supported by data comparing AD with normal aging, where we documented the same profile of damage, albeit with lower levels (Nunomura et al., 1999b). AD differs from other neurodegenerative diseases in that it shows exponential prevalence with aging. This makes AD a part of the normal aging process, which encompasses additional specific pathological mechanisms and suggests that many of the oxidative modifications resulting from aging also play a role in balancing systems underlying the metabolic abnormalities present in AD. Support for this idea comes from the analysis of lipid peroxidative modification of tau and neurofilament heavy subunit (NFH), two of the components of neurofibrillary tangles (Perry et al., 1985). Additionally, it was suggested that NFT are antioxidants since both tau and neurofilament protein appear uniquely adapted to oxidative attack, due to their high content of lysine-serineproline domains (Wataya et al., 2002). Exposure of these domains on the surface is affected by extensive phosphorylation of serine residues (Wataya et al., 2002; Liu et al., 2005). In AD, both tau and NFH are found as adducts of HNE, and the modifications are controlled by phosphorylation (Takeda et al., 2000b; Wataya et al., 2002). While NFH is modified by HNE at similar levels in AD and controls (Perry and Smith, unpublished data), normal brains present only small tau modifications (Takeda et al., 2000b). Tau modification by HNE greatly increases its ability to form filaments -in vitro (Pérez et al., 2000) and in cells (Pérez et al., 2002)- similar to those found in NFT. The link to phosphorylation and the known similarity of oxidative imbalance to induction of the MAP kinase pathway (Perry et al., 1999; Zhu et al., 2001b; Zhu et al., 2001a; Zhu et al., 2004) suggest that lipid peroxidation modification of tau is regulated by signal transduction pathways. Studies performed with rodents show that NFH-HNE levels do not increase with aging or movement of NFH to terminals, suggesting that levels of adduction are further regulated by removal 
or reversal of NFH-HNE adducts (Wataya et al., 2002). These data indicate this process may play a physiological role in axons, possibly protecting axonal components by scavenging toxic aldehydes formed during normal metabolism. This would be essential for axons, which cannot turn over and replace proteins as rapidly as cell bodies.

Transfection studies of neuroblastoma cells show that HO-1 expression is coordinated with tau phosphorylation, suggesting a physiological interaction between cytoskeleton reorganization and oxidation (Takeda et al., 2000a). In consideration of the enzymatic activity of HO-1 to produce iron and tau to bind iron (Sayre et al., 2000), the coordination may relate to iron homeostasis. These results clearly implicate a regulated process for modifications and responses. Changes such as HO-1 and MAP kinase pathway induction may be only a few of the many responses that interrelate to lipid peroxidative modifications. In this way, oxidative damage is no longer an end stage but rather a signal of underlying changes of state.

Furthermore, an antioxidant role for $A \beta$ in vivo is in agreement with recent data on the distribution of oxidative damage to $\mathrm{AD}$ neurons. 8-Hydroxyguanosine (8OHG), a major product of nucleic acid oxidation, markedly accumulates in the cytoplasm of cerebral neurons in AD. Unexpectedly, an increase in $\mathrm{A} \beta$ deposition in $\mathrm{AD}$ cortex is associated with a decrease in neuronal level of $8 \mathrm{OHG}$, i.e., with decreased oxidative damage (Nunomura et al., 1999a; Nunomura et al., 1999b). Similar negative correlation between $A \beta$ deposition and oxidative damage is found in patients with Down syndrome (Nunomura et al., 2000). Diffuse amyloid plaques may be considered as a compensatory response that reduces oxidative stress (Smith et al., 2000). The protective properties of $\mathrm{A} \beta$ could be related to its capacity to scavenge free radicals and the chelation of transition metals (Lovell et al., 1998; Unnikrishnan and Rao, 1990).

Altogether these findings suggest that both $A \beta$ and NFT, in the initial stages of AD development, may be compensations to combat increased oxidative stress.
Oxidative stress should be the target of future therapeutic strategies

Given the proximal role and devastating effect that oxidative stress plays in AD pathogenesis, a therapeutic strategy based on fighting oxidative stress appears reasonable. Certainly, such an assumption should be considered more reasonable than strategies based either on removal of $A \beta$ or on preventing the phosphorylation of tau, since both represent downstream consequences of oxidative stress and/or a concerted cellular effort to maintain homeostatic balance. In addition, data from the literature show that strategies envisaging the removal of $A \beta$ deposits (immunotherapy) have severe side effects, such as the activation of central nervous system inflammatory responses (Monsonego et al., 2003; Nicoll et al., 2003).

There is overwhelming clinical evidence that antioxidants, free radical fighters, slow the symptoms of both dementia and AD. Although modest, several epidemiological studies have shown lower risks of dementia and AD progression in people taking dietary antioxidants (Sano, 2003). However, the broad occurrence of AD (almost $50 \%$ by the age of 85), the non-regenerative nature of the CNS, and the fact that diagnosis often does not occur until late in disease progression, suggest that the ideal antioxidant should be used as prophylactic treatment in the aged population. Due to their low toxicity, low cost and their ability to target the earliest sources of oxidative stress in AD, antioxidant therapies are particularly attractive.

\section{CONCLUSIONS}

Instead of viewing oxidative stress as the breach of antioxidant defenses, we argue that this seldom happens in chronic conditions, pathological and physiological, and that a better understanding occurs by viewing each circumstance as a different, homeostatic balance in which reactive oxygen and nitrogen species play a key regulatory role. In the initial stages of AD development, neuronal cells, despite showing increased oxidative damage, may actually be in homeostatic balance. If cells 
survive and function in the presence of high levels of oxidative stress, it is because critical systems of cells are not damaged. In this way, detection of increased oxidative damage in cells that survive must be associated with a commensurate increase in compensatory mechanisms such as $\mathrm{A} \beta$ deposition and hyperphosphorylated tau. However, with the progression of $\mathrm{AD}$ and the consequent increase of reactive species levels, the efficient removal of A $\beta$-metal complexes and, probably, hyperphosphorylated tau would be overtaken by their disproportionably high generation, resulting in an uncontrollable growth of plaques and NFT and, consequently, an increase in reactive species generation. This would result in a feedback mechanism that could exacerbate plaque and NFT growth and reactive species generation, leading to a functional demise of neurons (Fig. 1).
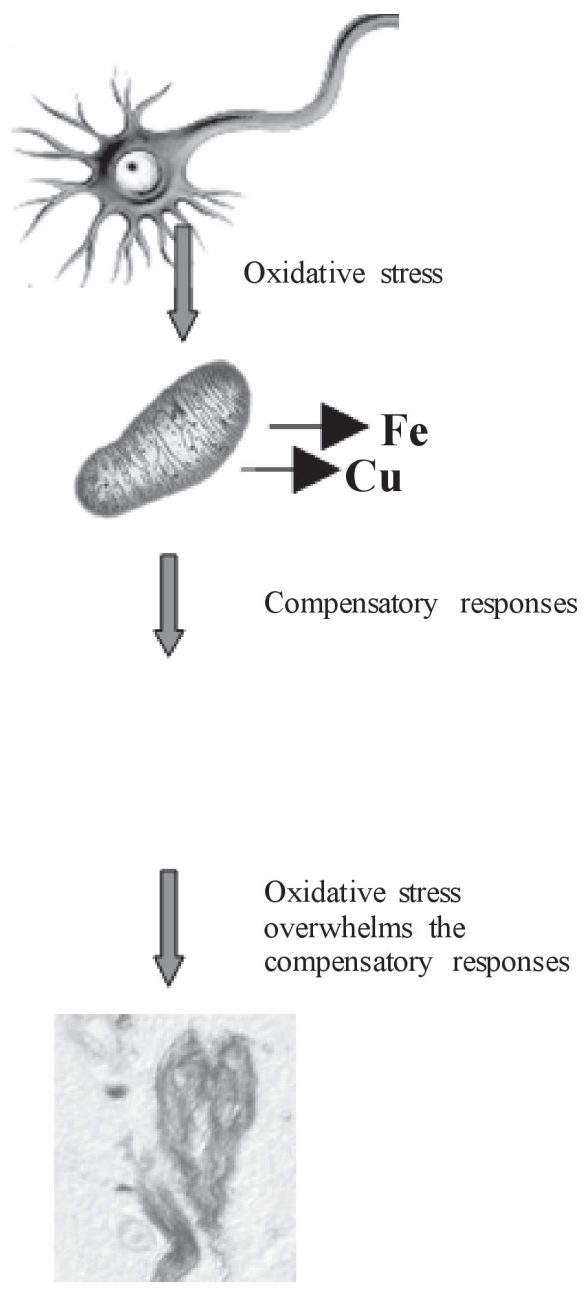

Neuronal damage and death

Figure 1. Possible sequence of neuronal events that occurs in AD. In the initial stages of AD, the increase in oxidative stress levels, mainly promoted by the interplay between the reactive species formed by mitochondria and the transition metals, induce neuronal compensatory responses and downstream adaptations, such as MAP kinase activation, A $\beta$ deposition and tau hyperphosphorylation, aimed to avoid neuronal damage and/or death. However, with the progression of $\mathrm{AD}$ and the consequent increase of reactive species levels, the efficient removal of A $\beta$-metal complexes and, probably, hyperphosphorylated tau would be overtaken by their disproportionably high generation, resulting in uncontrollable growth of plaques and NFT and consequently, an increase in reactive species generation. The increase in oxidative agents results, inevitably, in neuronal damage and death. 


\section{ACKNOWLEDGEMENTS}

This research was supported by the National Institutes of Health, Alzheimer's Association, and Philip Morris USA. Mark A. Smith and George Perry are consultants and own equity in Voyager Pharmaceuticals.

\section{REFERENCES}

CASH AD, ALIEV G, SIEDLAK SL, NUNOMURA A, FUJIOKA H, ZHU X, RAINA AK, VINTERS HV, TABATON M, JOHNSON AB, PAULA-BARBOSA M, ÁVILA J, JONES PK, CASTELLANI RJ, SMITH MA, PERRY G (2003) Microtubule reduction in Alzheimer's disease and aging is independent of tau filament formation. Am J Pathol 162: 1623-1627

CASTELlANI R, HIRAI K, ALIEV G, DREW KL, NUNOMURA A, TAKEDA A, CASH AD, OBRENOVICH ME, PERRY G, SMITH MA (2002) Role of mitochondrial dysfunction in Alzheimer's disease. J Neurosci Res 70: 357-360

CASTELLANI RJ, HARRIS PL, SAYRE LM, FUJII J, TANIGUCHI N, VITEK MP, FOUNDS H, ATWOOD CS, PERRY G, SMITH MA (2001) Active glycation in neurofibrillary pathology of Alzheimer disease: N(epsilon)-(carboxymethyl) lysine and hexitol-lysine. Free Radic Biol Med 31: 175-180

HIRAI K, ALIEV G, NUNOMURA A, FUJIOKA H, RUSSELL RL, ATWOOD CS, JOHNSON AB, KRESS Y, VINTERS HV, TABATON M, SHIMOHAMA S, CASH AD, SIEDLAK SL, HARRIS PL, JONES PK, PETERSEN RB, PERRY G, SMITH MA (2001) Mitochondrial abnormalities in Alzheimer's disease. J Neurosci 21: 3017-3023

HONDA K, CASADESUS G, PETERSEN RB, PERRY G, SMITH MA (2004) Oxidative stress and redox-active iron in Alzheimer's disease. Ann N Y Acad Sci 1012: 179-182

KALARIA RN, GRAVINA SA, SCHMIDLEY JW, PERRY G, HARIK SI (1988) The glucose transporter of the human brain and blood-brain barrier. Ann Neurol 24: 757-764

KEYSE SM, TYRRELL RM (1989) Heme oxygenase is the major 32-kDa stress protein induced in human skin fibroblasts by UVA radiation, hydrogen peroxide, and sodium arsenite. Proc Natl Acad Sci U S A 86: 99-103

LIU Q, LEE HG, HONDA K, SIEDLAK SL, HARRIS PL, CASH AD, ZHU X, ÁVILA J, NUNOMURA A, TAKEDA A, SMITH MA, PERRY G (2005) Tau modifiers as therapeutic targets for Alzheimer's disease. Biochem Biophys Acta 1739: 211-215

LOVELL MA, ROBERTSON JD, TEESDALE WJ, CAMPBELL JL, MARKESBERY WR (1998) Copper, iron and zinc in Alzheimer's disease senile plaques. J Neurol Sci 158: 47-52

MAYEUX R, SANO M (1999) Treatment of Alzheimer's disease. N Engl J Med 341: 1670-1679

MONSONEGO A, ZOTA V, KARNI A, KRIEGER JI, BAR-OR A, BITAN G, BUDSON AE, SPERLING R, SELKOE DJ, WEINER HL (2003) Increased T cell reactivity to amyloid beta protein in older humans and patients with Alzheimer disease. J Clin Invest 112: $415-422$
MONTINE TJ, AMARNATH V, MARTIN ME, STRITTMATTER WJ, GRAHAM DG (1996) E-4hydroxy-2-nonenal is cytotoxic and cross-links cytoskeletal proteins in P19 neuroglial cultures. Am J Pathol 148: 89-93

NICOLL JA, WILKINSON D, HOLMES C, STEART P, MARKHAM H, WELLER RO (2003) Neuropathology of human Alzheimer disease after immunization with amyloid-beta peptide: a case report. Nat Med 9: 448452

NUNOMURA A, CHIBA S, LIPPA CF, CRAS P, KALARIA RN, TAKEDA A, HONDA K, SMITH MA, PERRY G (2004) Neuronal RNA oxidation is a prominent feature of familial Alzheimer's disease. Neurobiol Dis 17: 108-113

NUNOMURA A, PERRY G, ALIEV G, HIRAI K, TAKEDA A, BALRAJ EK, JONES PK, GHANBARI $\mathrm{H}$, WATAYA $\mathrm{T}$, SHIMOHAMA S, CHIBA $\mathrm{S}$, ATWOOD CS, PETERSEN RB, SMITH MA (2001) Oxidative damage is the earliest event in Alzheimer disease. J Neuropathol Exp Neurol 60: 759-767

NUNOMURA A, PERRY G, HIRAI K, ALIEV G, TAKEDA A, CHIBA S, SMITH MA (1999a) Neuronal RNA oxidation in Alzheimer's disease and Down's syndrome. Ann N Y Acad Sci 893: 362-364

NUNOMURA A, PERRY G, PAPPOLLA MA, FRIEDLAND RP, HIRAI K, CHIBA S, SMITH MA (2000) Neuronal oxidative stress precedes amyloidbeta deposition in Down syndrome. J Neuropathol Exp Neurol 59: 1011-1017

NUNOMURA A, PERRY G, PAPPOLLA MA, WADE R, HIRAI K, CHIBA S, SMITH MA (1999b) RNA oxidation is a prominent feature of vulnerable neurons in Alzheimer's disease. J Neurosci 19: 1959-1964

PÉREZ M, CUADROS R, SMITH MA, PERRY G, ÁVILA J (2000) Phosphorylated, but not native, tau protein assembles following reaction with the lipid peroxidation product, 4-hydroxy-2-nonenal. FEBS Lett 486: $270-274$

PÉREZ M, HERNÁNDEZ F, GÓMEZ-RAMOS A, SMITH M, PERRY G, ÁVILA J (2002) Formation of aberrant phosphotau fibrillar polymers in neural cultured cells. Eur J Biochem 269: 1484-1489

PERRY G, NUNOMURA A, LUCASSEN P, LASSMANN H, SMITH MA (1998a) Apoptosis and Alzheimer's disease. Science 282: 1268-1269

PERRY G, NUNOMURA A, SMITH MA (1998b) A suicide note from Alzheimer disease neurons? Nat Med 4: 897-898

PERRY G, RIZZUTO N, AUtilio-GAMBETTI L, GAMBETTI P (1985) Paired helical filaments from Alzheimer disease patients contain cytoskeletal components. Proc Natl Acad Sci U S A 82: 3916-3920

PERRY G, RODER H, NUNOMURA A, TAKEDA A, FRIEDLICH AL, ZHU X, RAINA AK, HOLBROOK N, SIEDLAK SL, HARRIS PL, SMITH MA (1999) Activation of neuronal extracellular receptor kinase (ERK) in Alzheimer disease links oxidative stress to abnormal phosphorylation. Neuroreport 10: 2411-2415

PERRY G, TADDEO MA, NUNOMURA A, ZHU X, ZENTENO-SAVIN T, DREW KL, SHIMOHAMA S, ÁVILA J, CASTELLANI RJ, SMITH MA (2002) Comparative biology and pathology of oxidative stress in Alzheimer and other neurodegenerative diseases: beyond damage and response. Comp Biochem Physiol C Toxicol Pharmacol 133: 507-513

PREMKUMAR DR, SMITH MA, RICHEY PL, PETERSEN RB, CASTELLANI R, KUTTY RK, WIGGERT B, PERRY G, KALARIA RN (1995) Induction of heme oxygenase-1 mRNA and protein in 
neocortex and cerebral vessels in Alzheimer's disease. J Neurochem 65: 1399-1402

SANO M (2003) Current concepts in the prevention of Alzheimer's disease. CNS Spectr 8: 846-853

SAYRE LM, PERRY G, HARRIS PL, LIU Y, SCHUBERT KA, SMITH MA (2000) In situ oxidative catalysis by neurofibrillary tangles and senile plaques in Alzheimer's disease: A central role for bound transition metals. J Neurochem 74: 270-279

SAYRE LM, ZELASKO DA, HARRIS PL, PERRY G, SALOMON RG, SMITH MA (1997) 4Hydroxynonenal-derived advanced lipid peroxidation end products are increased in Alzheimer's disease. J Neurochem 68: 2092-2097

SMITH MA, HARRIS PL, SAYRE LM, PERRY G (1997a) Iron accumulation in Alzheimer disease is a source of redox-generated free radicals. Proc Natl Acad Sci U S A 94: 9866-9868

SMITH MA, JOSEPH JA, PERRY G (2000) Arson. Tracking the culprit in Alzheimer's disease. Ann N Y Acad Sci 924: 35-38

SMITH MA, RICHEY HARRIS PL, SAYRE LM, BECKMAN JS, PERRY G (1997b) Widespread peroxynitrite-mediated damage in Alzheimer's disease. J Neurosci 17: 2653-2657

SMITH MA, SAYRE LM, MONNIER VM, PERRY G (1995) Radical AGEing in Alzheimer's disease. Trends Neurosci 18: 172-176

SMITH MA, TANEDA S, RICHEY PL, MIYATA S, YAN SD, STERN D, SAYRE LM, MONNIER VM, PERRY G (1994) Advanced Maillard reaction end products are associated with Alzheimer disease pathology. Proc Natl Acad Sci U S A 91: 5710-5714

TAKEDA A, ITOYAMA Y, KIMPARA T, ZHU X, ÁVILA J, DWYER BE, PERRY G, SMITH MA (2004) Heme catabolism and heme oxygenase in neurodegenerative disease. Antioxid Redox Signal 6: 888-894
TAKEDA A, PERRY G, ABRAHAM NG, DWYER BE, KUTTY RK, LAITINEN JT, PETERSEN RB, SMITH MA (2000a) Overexpression of heme oxygenase in neuronal cells, the possible interaction with Tau. J Biol Chem 275: 5395-5399

TAKEDA A, SMITH MA, ÁVILA J, NUNOMURA A, SIEDLAK SL, ZHU X, PERRY G, SAYRE LM (2000b) In Alzheimer's disease, heme oxygenase is coincident with Alz50, an epitope of tau induced by 4hydroxy-2-nonenal modification. J Neurochem 75: 1234-1241

UNNIKRISHNAN MK, RAO MN (1990) Antiinflammatory activity of methionine, methionine sulfoxide and methionine sulfone. Agents Actions 31: $110-112$

WALLACE DC (1999) Mitochondrial diseases in man and mouse. Science 283: 1482-1488

WATAYA T, NUNOMURA A, SMITH MA, SIEDLAK SL, HARRIS PL, SHIMOHAMA S, SZWEDA LI, KAMINSKI MA, ÁVILA J, PRICE DL, CLEVELAND DW, SAYRE LM, PERRY G (2002) High molecular weight neurofilament proteins are physiological substrates of adduction by the lipid peroxidation product hydroxynonenal. J Biol Chem 277: 4644-4648

ZHU X, RAINA AK, LEE HG, CASADESUS G, SMITH MA, PERRY G (2004) Oxidative stress signalling in Alzheimer's disease. Brain Res 1000: 32-39

ZHU X, RAINA AK, ROTTKAMP CA, ALIEV G, PERRY G, BOUX H, SMITH MA (2001a) Activation and redistribution of c-jun $\mathrm{N}$-terminal kinase/stress activated protein kinase in degenerating neurons in Alzheimer's disease. J Neurochem 76: 435-441

ZHU X, ROTTKAMP CA, HARTZLER A, SUN Z, TAKEDA A, BOUX H, SHIMOHAMA S, PERRY G, SMITH MA (2001b) Activation of MKK6, an upstream activator of $\mathrm{p} 38$, in Alzheimer's disease. J Neurochem 79: $311-318$ 